\title{
ATIVIDADES PEDAGÓGICAS NA PROMOÇÃO DA APRENDIZAGEM ATIVA DOS ESTUDANTES DE GRADUAÇÃO NAS DISCIPLINAS DE ESTATÍSTICA
}

\section{PEDAGOGICAL ACTIVITIES IN PROMOTING ACTIVE LEARNING OF GRADUATE STUDENTS IN STATISTICAL DISCIPLINES}

Suzi Samá ${ }^{1}$

\begin{abstract}
Resumo: Este relato de experiência apresenta três atividades planejadas para instigar o interesse do estudante do Ensino Superior pela Estatística e promover sua aprendizagem ativa em sala de aula. No seu planejamento e desenvolvimento, consideraram-se os pressupostos da Teoria da Biologia do Conhecer e da Neurociência Cognitiva, para que os estudantes se percebam como produtores de conhecimento e corresponsáveis pelo seu processo de aprendizagem. De diferentes formas, as três atividades viabilizaram uma participação ativa dos estudantes, que perderam o receio pela disciplina e participaram de debates e discussões potencializados pela metodologia de ensino adotada. Conclui-se que repensar a prática pedagógica pode levar o professor a encontrar formas de ajudar os estudantes a superar suas dificuldades de compreensão dos conceitos estatísticos.
\end{abstract}

Palavras-chave: Educação Estatística; Aprendizagem Ativa; Atividades Pedagógicas; Neurociência Cognitiva; Teoria da Biologia do Conhecer.

\begin{abstract}
This experience report presents three activities designed to arouse the interest of higher education students in statistics and to promote their active learning in the classroom. In its planning and development, we considered the assumptions of the Theory of Knowledge Biology and Cognitive Neuroscience, so that students perceive themselves as knowledge producers and co-responsible for their learning process. In different ways, the three activities enabled the active participation of students, who lost their fear of the discipline and participated in debates and discussions enhanced by the teaching methodology adopted. It is concluded that rethinking pedagogical practice can lead the teacher to find ways to help students overcome their difficulties in understanding statistical concepts.
\end{abstract}

Keywords: Statistical Education; Active Learning; Pedagogical Activities; Cognitive Neuroscience; Theory of Biology of Knowing.

\section{0 ser e o fazer docente na sala de aula de Estatística}

A aplicação da Estatística na tomada de decisões a partir de dados nas diversas áreas do conhecimento impulsionou sua inserção no currículo dos cursos do Ensino Superior (CAZORLA; SILVA JÚNIOR; SANTANA, 2018). Por disponibilizar métodos e técnicas que possibilitam extrair informações a partir de dados, a Estatística auxilia a compreender o mundo que nos cerca, seja na previsão do tempo, na intenção de voto de um candidato, no risco de crédito bancário, no valor do seguro do carro, entre tantas outras

\footnotetext{
${ }^{1}$ Doutorado em Educação em Ciências pela Universidade Federal do Rio Grande (FURG). Professora Adjunta da Universidade Federal do Rio Grande (FURG), Rio Grande, Rio Grande do Sul, Brasil. E-mail: suzisama@furg.br
} 


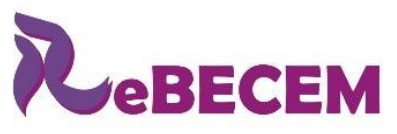

Revista Brasileira de Educação em

Ciências e Educação Matemática

DOI: http://dx.doi.org/10.33238/ReBECEM.2019.v.3.n.2.22636

situações do nosso dia a dia. Assim, segundo Gal (2002), tornamo-nos consumidores de dados quando lemos e ouvimos anúncios e informações divulgados pela mídia impressa e digital, ou ainda no local de trabalho, quando lemos relatórios e documentos. Para o autor, vivemos em ambientes carregados de informações estatísticas, seja por meio de tabelas, gráficos, números ou texto.

Apesar da notória importância da Estatística em nosso dia a dia e no meio científico, na sala de aula o que temos observado são estudantes de graduação com dificuldade em compreender os conceitos dessa ciência. Para Cordani (2015), essa dificuldade, em parte, ocorre devido à abordagem formal na introdução dos conceitos estatísticos, com ênfase em aplicação de fórmulas e resolução de cálculos, pelos profissionais responsáveis pelo ensino dessa ciência nos cursos de graduação.

Minha experiência como professora de Estatística no Ensino Superior não foi diferente. Quando me deparei com o desafio de ensinar os conceitos estatísticos, por mais que planejasse e preparasse minhas aulas, percebia que os estudantes não os compreendiam. Aos poucos fui notando que o método de ensino que adotava não os ajudava no seu processo de aprendizagem. As estratégias pedagógicas e as metodologias de ensino que vivenciei como aluna, em minha formação na Licenciatura em Matemática, ainda eram fortemente influenciadas pelo determinismo, pelo racionalismo e pelo mecanicismo, sem considerar a variabilidade e o indeterminismo inerente aos fenômenos aleatórios. Dessa forma, no trabalho docente com Estatística, eu seguia o modelo de professor que tive, com foco na aplicação de fórmulas e na resolução de cálculos.

A dificuldade dos estudantes em compreender os conceitos estatísticos gerou inquietações em relação ao meu ser/fazer docente e me conduziu ao seguinte questionamento: Afinal, como aprendemos? Na busca por uma reposta, encontrei a Teoria da Biologia do Conhecer, proposta por Maturana e Varela (2005), e os estudos da Neurociência Cognitiva, os quais possibilitaram repensar minha prática pedagógica.

Segundo a base epistemológica trazida por Maturana e Varela (2005), aprender é um processo de adaptação que depende da estrutura interna do indivíduo e das interações que fazemos com o meio. Para esses teóricos e neurocientistas, o sistema nervoso dos seres vivos não processa informações provenientes do mundo exterior - pelo contrário, cria um mundo no processo da cognição. No campo neurocientífico a aprendizagem consiste na "capacidade de associar as informações sensoriais à memória e à cognição de modo a formar conceitos sobre o mundo, sobre nós mesmos e orientar nosso comportamento" (LENT, 2001, p. 557). 
DOI: http://dx.doi.org/10.33238/ReBECEM.2019.v.3.n.2.22636

Para Maturana (2006), o que aprendemos e o modo como aprendemos dependem das emoções e de nosso viver. Dessa forma, toda ação ou decisão é fundamentada e ou sustentada por uma emoção, pois as emoções conferem sentido e significação às ações. Tyng et al., (2017) ressaltam que a emoção viabiliza a formação de memórias de longo prazo no contexto acadêmico, visto que ela modula o sistema atencional de modo a influenciar o processamento cognitivo da informação. Segundo Gazzaniga et al. (2006), a atenção é um mecanismo cerebral cognitivo que possibilita processar determinadas informações, pensamentos ou ações, enquanto ignora outros irrelevantes.

Por mais que a informação esteja acessível, o conhecimento que cada indivíduo constrói é produto da inter-relação entre interpretar e compreender a informação recebida (VALENTE, 2014). Para Moran (2018, p. 2):

\begin{abstract}
A aprendizagem é ativa e significativa quando avançamos em espiral, de níveis mais simples para mais complexos de conhecimento e competência em todas as dimensões da vida. Esses avanços realizam-se por diversas trilhas com movimentos, tempos e desenhos diferentes, que se integram como mosaicos dinâmicos, com diversas ênfases, cores e sínteses, frutos das interações pessoais, sociais e culturais em que estamos inseridos.
\end{abstract}

Assim, em minha prática pedagógica, busco planejar atividades que potencializem uma atitude ativa do estudante e abarquem o contexto vivido por eles, de forma a potencializar a aprendizagem dos conceitos estatísticos. Para Rodrigues (2016, p. 3), a aprendizagem consiste no processo pelo qual o conhecimento é adquirido e/ou modificado, "tem início na estimulação sensorial e termina com o seu armazenamento e recuperação (memória), através da representação interna que criamos das informações recebidas".

Com esse entendimento, neste relato apresento três atividades desenvolvidas de forma a promover o processo de aprendizagem dos conceitos estatísticos, planejadas em função do cenário apresentado nesta seção e voltadas para sua socialização, de forma a possibilitar que outros docentes repensem sua prática pedagógica nas disciplinas de Estatística. Ao longo do presente relato, evidencio alguns aspectos da Teoria da Biologia do Conhecer e da Neurociência Cognitiva que fundamentam minha prática docente.

\title{
2 Atividades pedagógicas planejadas para a sala de aula de Estatística
}

Nesta seção relato três atividades planejadas e desenvolvidas para as disciplinas de Estatística que ministro para diferentes cursos de graduação da Universidade Federal do Rio Grande - FURG. A primeira delas, intitulada "Quem sou eu?", vem sendo 


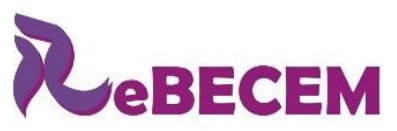

Revista Brasileira de Educação em

Ciências e Educação Matemática

DOI: http://dx.doi.org/10.33238/ReBECEM.2019.v.3.n.2.22636

desenvolvida na sala de aula de Estatística de vários cursos de graduação, como Administração, Licenciatura em Matemática, Licenciatura em Ciências Biológicas, Tecnólogo em Gestão Ambiental e Enfermagem. Seu objetivo é promover maior integração entre a professora e a turma, além de possibilitar ao estudante compreender o processo de coleta e organização de dados de forma descontraída.

Na segunda atividade, o Modelo de Rotação por Estações foi desenvolvido na disciplina de Ensino de Estatística para Licenciaturas, criada no segundo semestre de 2017 para ser ofertada como disciplina optativa ou complementar em todas as Licenciaturas da Instituição. No Modelo de Rotação por Estações são explorados diversos recursos didáticos no trabalho dos conceitos estatísticos, de forma a mostrar aos futuros professores diferentes maneiras de planejar a sala de aula.

A terceira atividade, intitulada Projetos de Aprendizagem (PA), consiste no ensino de Estatística pela pesquisa. Ela já foi desenvolvida em vários cursos, como Administração, Ciências Econômicas, Ciências Contábeis e, mais recentemente, na Enfermagem, em Gestão Ambiental e Licenciatura em Ciências Biológicas. Em um PA, o estudante escolhe um tema de seu interesse e vivencia as diferentes etapas de uma pesquisa estatística. Todas as três atividades foram planejadas e desenvolvidas de forma a promover uma atitude mais ativa dos estudantes nas aulas. A seguir, cada uma delas será detalhada.

\subsection{Atividade 1: Quem sou eu?}

No primeiro dia de aula, a clássica apresentação da professora é substituída pela atividade "Quem sou eu?"2. Os estudantes, por meio de recursos visuais, são instigados a responder perguntas sobre características da professora, como altura, cor preferida, principal fonte de informação, comida predileta, animal de estimação (Figura 1). Essa atividade foi planejada, considerando que a apreensão do registro de informações sobre um determinado assunto é facilitada com o uso de imagens visuais, além da forma verbal (COSENZA; GUERRA, 2011).

\footnotetext{
${ }^{2}$ Mais detalhes sobre essa atividade podem ser obtidos em Samá et al., (2019).
} 


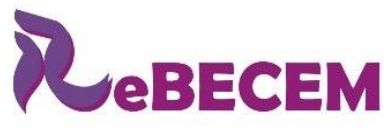

DOI: http://dx.doi.org/10.33238/ReBECEM.2019.v.3.n.2.22636

\section{Ciências e Educação Matemática \\ ISSN 2594-9179}

Revista Brasileira de Educação em

Figura 1: Slides da atividade "Quem sou eu?"
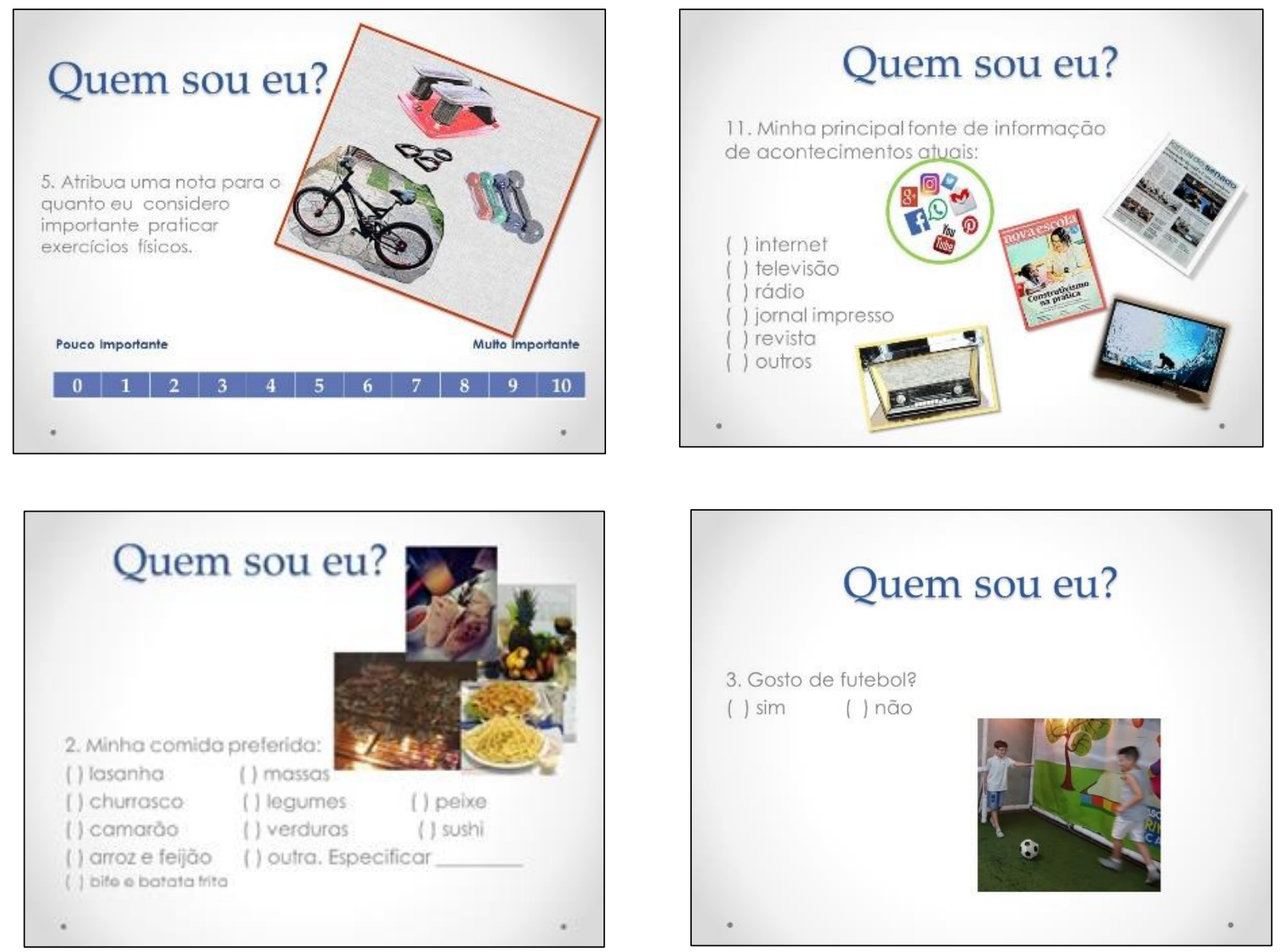

Fonte: Acervo pessoal da Professora Suzi Samá

As perguntas representam diferentes tipos de variáveis, qualitativas ou quantitativas, bem como adotam diversas escalas, de forma a explorar os conceitos estatísticos a serem trabalhados na disciplina. Ao longo da atividade, a professora vai discutindo com os estudantes sobre as diferentes variáveis e escalas abordadas nas perguntas, instigando-os a dar sugestões sobre outras formas de coletar os dados. As respostas dos estudantes são digitadas em uma planilha eletrônica, a fim de que os dados possam ser organizados e apresentados em tabelas, gráficos e por meio de medidas estatísticas. Dependendo dos recursos digitais disponíveis, pode ser elaborado um questionário on-line, o que facilita o registro dos dados e o acesso para utilização pelos estudantes em atividades futuras.

A curiosidade dos estudantes em conhecer a opinião da turma sobre os hábitos e as características da professora ativa a função cognitiva "atenção", o que facilita aos estudantes reter na memória as informações estatísticas. Por esse motivo, ao longo da apresentação dos resultados, é importante que sejam debatidos diferentes aspectos dos conceitos estatísticos implicados tanto na coleta quanto na organização dos dados. Na 


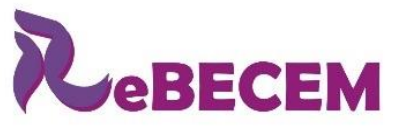

\section{Revista Brasileira de Educação em \\ Ciências e Educação Matemática}

DOI: http://dx.doi.org/10.33238/ReBECEM.2019.v.3.n.2.22636

apresentação das variáveis qualitativas foram utilizadas tabelas e gráficos, e para as variáveis quantitativas foram empregadas distribuições de frequência e medidas estatísticas como média, mediana, moda e desvio-padrão (Figura 2 e 3). Essas diferentes formas de organizar os dados foram debatidas com os estudantes, que revelaram o que conheciam de cada uma delas.

Figura 2: Slides dos itens 1 e 8 do questionário da atividade "Quem sou eu?"
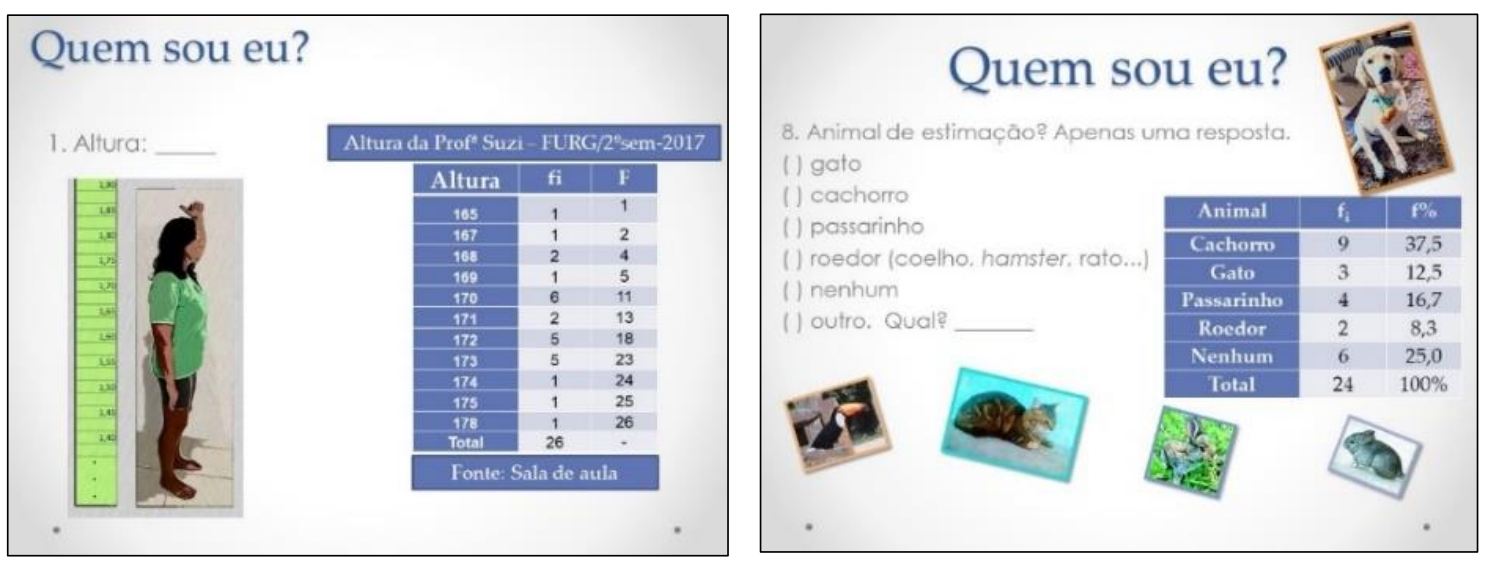

Fonte: Acervo pessoal da Professora Suzi Samá

Figura 3: Slides dos itens 2 e 6 do questionário da atividade "Quem sou eu?"
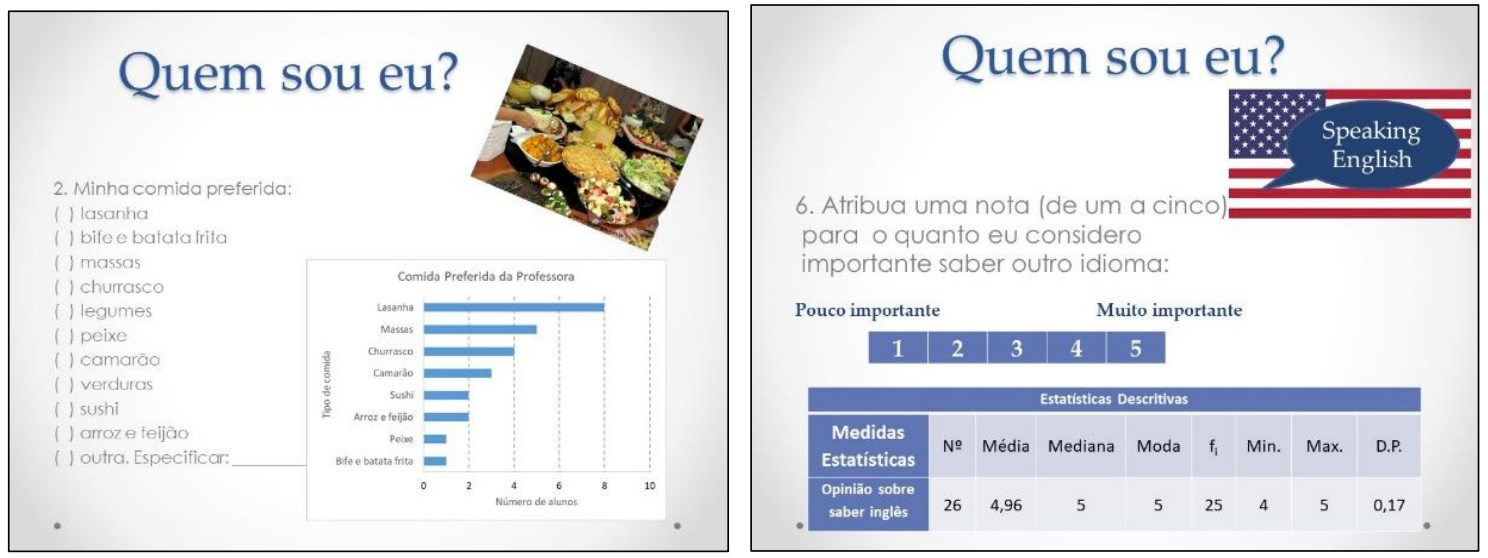

Fonte: Acervo pessoal da Professora Suzi Samá (2017)

Ao longo de todo o trabalho, os alunos assumiram uma atitude ativa no processo de aprendizagem. A diferente forma de conhecer a professora trouxe elementos novos para o ambiente da sala de aula, o que, segundo Cosenza e Guerra (2011), possibilita capturar a atenção dos estudantes para os conceitos abordados. O planejamento da atividade também considerou que manter a atenção demanda ativar circuitos neurais específicos, o que exige diferentes estímulos ao longo da aula, já que após algum tempo 


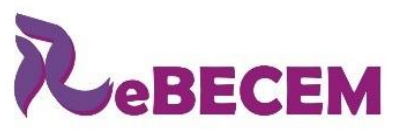

Revista Brasileira de Educação em

Ciências e Educação Matemática

ISSN 2594-9179

DOI: http://dx.doi.org/10.33238/ReBECEM.2019.v.3.n.2.22636

o foco atencional pode ser desviado tanto por estímulos do ambiente quanto por processos centrais, como o pensamento.

Para que os estudantes mantenham o foco, é fundamental que o professor utilize outros recursos nas próximas aulas. Assim, em outra aula a planilha com os dados digitados foi impressa, de forma que os estudantes, em grupo, organizassem tabelas e gráficos com os dados, com o auxílio de transferidor, régua, compasso e lápis de cor. Apesar de serem alunos do Ensino Superior, todos ficaram muito envolvidos com a construção dos gráficos no recurso papel e lápis. A fim de debater com os estudantes sobre a forma mais adequada de representar os dados de acordo com as características do gráfico e o tipo de variável, os gráficos e as tabelas elaborados pelos estudantes foram digitalizados e apresentados à turma para discussão.

É importante destacar que a atividade “Quem sou eu?" tem por objetivo realizar uma exposição prévia dos conceitos básicos de estatística, envolvendo aspectos do cotidiano do estudante. Isso porque o cérebro só está disposto a aprender aquilo que tem ligação com o que já é conhecido (COSENZA; GUERRA, 2011). Os dados produzidos nessa atividade podem ser utilizados em diferentes momentos da disciplina, a fim de evidenciar certos aspectos sobre os conceitos estatísticos previstos na ementa.

\subsection{Atividade 2: Rotação por Estações}

O Modelo de Rotação por Estações permite que o estudante passe algum tempo imerso em diferentes estações de ensino. Em pelo menos uma delas a atividade proposta é on-line (ANDRADE; SOUZA, 2016). Cada estação tem uma atividade diferente, e os estudantes, organizados em grupos, percorrem todas e realizam as atividades planejadas pelo professor, que não seguem necessariamente uma ordem de execusão: são, de certa forma, independentes, mas todos os estudantes passam por cada uma das estações, discutindo as atividades, de forma que os momentos de trabalho colaborativo nos grupos de estudantes sejam valorizados (BACICH; MORAN, 2015).

Com efeito, na disciplina de Ensino de Estatística para Licenciaturas, a maioria das estações foram organizadas de modo que cada uma abordasse diferentes aspectos sobre os conceitos estatísticos previstos para o Ensino Médio, e os estudantes, reunidos em grupo, realizaram as atividades propostas em cada uma delas. Como alguma pode demandar mais tempo do que outras, é interessante que o número de estações seja maior do que o de grupos de estudantes, de forma a evitar que algum grupo fique parado, 


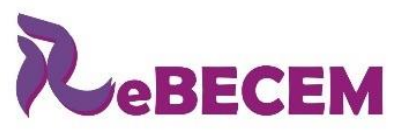

Revista Brasileira de Educação em
Ciências e Educação Matemática

DOI: http://dx.doi.org/10.33238/ReBECEM.2019.v.3.n.2.22636

esperando os outros terminarem as atividades. Outra maneira de evitar isso, adotada na disciplina, é deixar duas estações com atividades repetidas.

As estações trabalhavam os seguintes conceitos estatísticos: medidas de tendência central, probabilidade, erros gráficos e questões do Exame Nacional do Ensino Médio ENEM. Todas tratavam de conceitos previstos para o Ensino Médio. Na estação com atividade on-line foram explorados os conceitos de medidas de tendência central, utilizando o fórum on-line de materiais do Software Geogebra ${ }^{3}$. Neste relato descrevo apenas as estações referentes aos dois últimos conceitos: erros gráficos e questões do ENEM.

Uma das estações tinha como proposta o trabalho com gráficos divulgados pela mídia televisiva nacional e internacional, os quais apresentavam algum tipo de erro (Figura 4). Os estudantes eram convidados a examinar os gráficos e identificar o erro cometido na sua construção. A atividade foi planejada de forma a promover a reflexão sobre a utilização da representação gráfica na divulgação das informações pela mídia. Cazorla (2004, p. 2) destaca que o uso da Estatística "nem sempre respeita os princípios éticos da divulgação científica”.

No gráfico que retrata a Inflação do Brasil no período de 2009 a 2013 podemos observar que a altura das barras e as porcentagens não estão coerentes. A inflação em 2013 é representada, na altura da coluna do gráfico, como sendo superior à inflação de 2011; no entanto, se olharmos as porcentagens, vemos que em $2013(5,91 \%)$ a inflação foi menor que em 2011 (6,50\%). Além disso, a inflação de 2013 (5,91\%), apesar de ser menor do que a de 2010 (5,92\%), apresenta coluna mais alta no gráfico.

Souza e Silva (2019) também utilizam os erros gráficos apresentados na mídia como atividade motivacional, a fim de provocar discussões e reflexões sobre as informações apresentadas pela mídia. Segundo os autores, os gráficos com erros oferecem um excelente ferramental para contextualizar a Estatística e promover uma análise crítica das informações estatísticas.

\footnotetext{
${ }^{3}$ Mais detalhes dessa atividade podem ser encontrados em Samá, Moura e Santos (2019)
} 


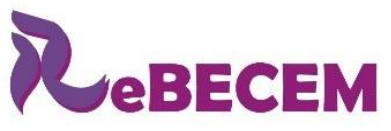

DOI: http://dx.doi.org/10.33238/ReBECEM.2019.v.3.n.2.22636

Figura 4: Gráficos com erros apresentados na mídia nacional e internacional
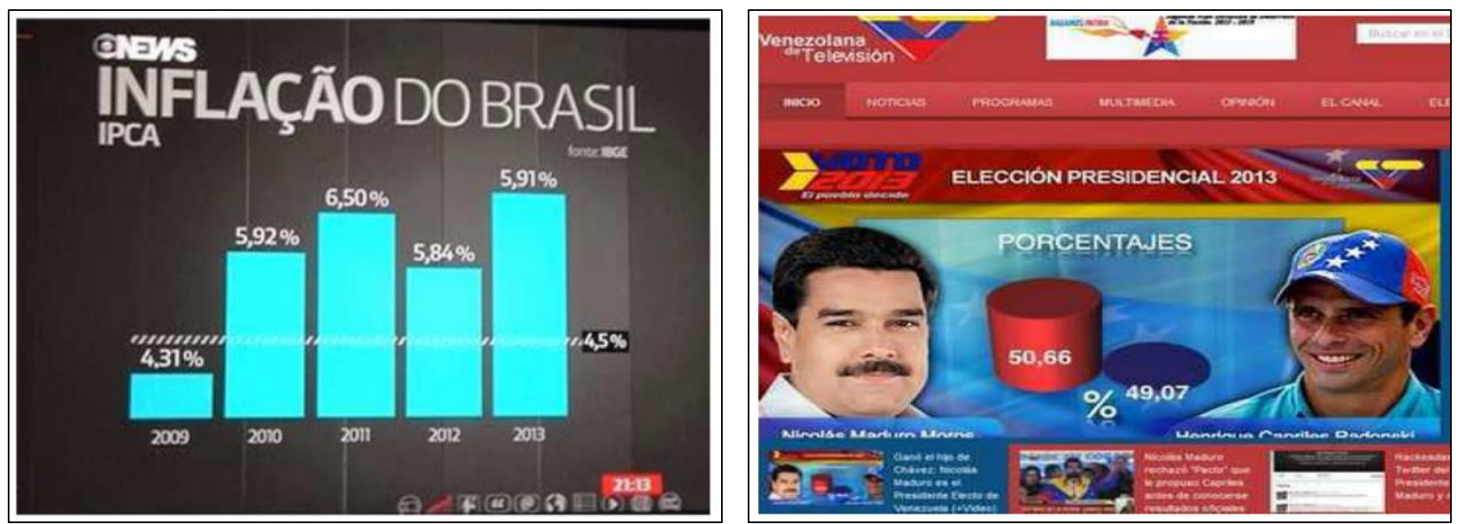

Fonte: Arquivo pessoal da Professora Suzi Samá

O gráfico que retrata o resultado das eleições presidenciais de 2013 na Venezuela evidencia claramente a manipulação da escala, uma vez que visualmente a diferença de votos entre os candidatos aparenta ser bem maior do que a numérica, de apenas 1,59 pontos percentuais. Em pesquisa sobre o uso de gráficos na mídia impressa, Cavalcanti, Natrielli e Guimarães (2010, p.749) constataram que 39\% dos gráficos analisados contêm erros de proporcionalidade entre os valores apresentados, o que pode "demonstrar uma intenção de se manipular, omitir ou até mesmo mascarar os dados".

Importa também considerar que, em alguns casos, mesmo sem intenção, a informação pode mostrar uma realidade camuflada, o que, muitas vezes, induz o cidadão a tomar decisões equivocadas. Por essa razão, atividades que envolvam a análise crítica das informações estatísticas disponibilizadas na mídia são fundamentais para a formação de um cidadão crítico e responsável, capaz de tomar decisões conscientes em um mundo permeado pela informação estatística.

Campos et al., (2015) destacam que a estratégia de utilizar gráficos com erros divulgados na mídia foi favorável ao engajamento dos alunos na atividade proposta na aula. Também ficaram evidentes a reação e a satisfação deles em aprender ao mesmo tempo em que discutiam problemas atuais.

Outra estação continha questões do Exame Nacional do Ensino Médio - ENEM de 2016, que aplicavam a interpretação de dados estatísticos, como as apresentadas na Figura 5. Pereira e Souza (2016, p. 1339) salientam que as "questões do ENEM devem envolver não só o reconhecimento dos conteúdos estatísticos, mas também a sua interpretação, junto com a habilidade do raciocínio na resolução de problemas”. 
Figura 5: Questões do Exame Nacional do Ensino Médio

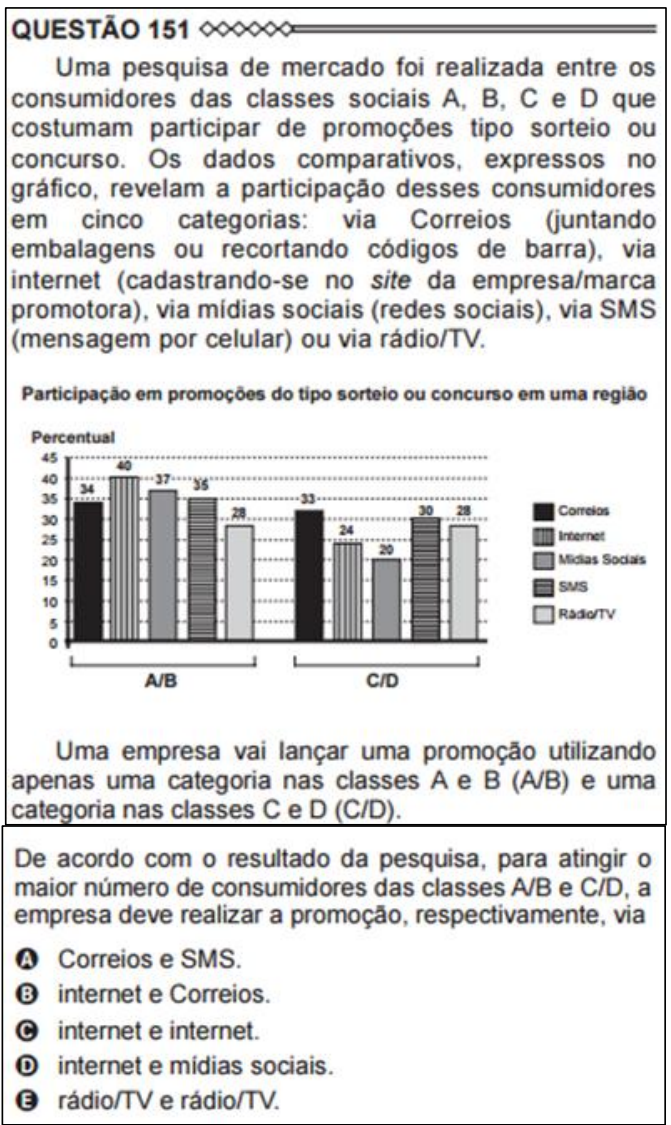

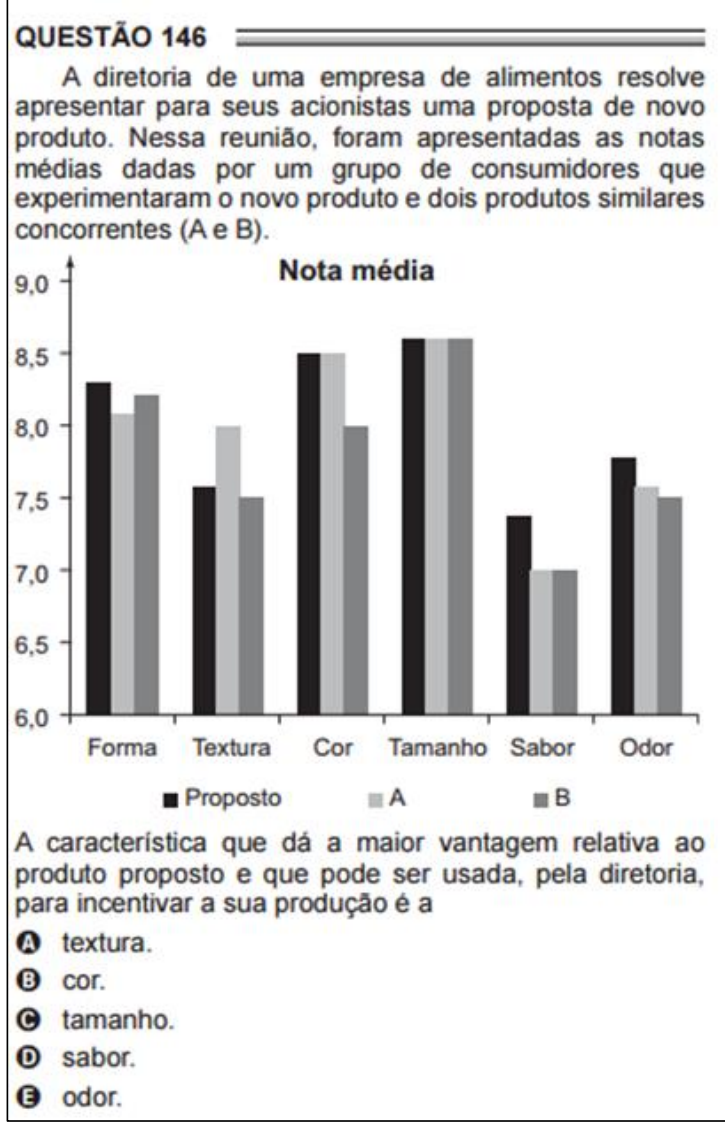

Fonte: Arquivo pessoal da Professora Suzi Samá

Essa estação foi planejada para possibilitar ao estudante refletir sobre os conceitos estatísticos que já deveriam ter sido trabalhados na Educação Básica, bem como sobre a importância de conhecer as diferentes formas de apresentar e organizar os dados de uma pesquisa. Goulart e Coutinho (2015), ao analisarem as questões que abordam conteúdos de Estatística no ENEM no período de 2009 a 2012, constataram maior concentração de propostas que solicitam a interpretação de tabelas e gráficos, sendo pouco exigida a interpretação de medidas de posição e dispersão. Os autores ainda salientam que a interpretação de gráficos demanda, em geral, sua leitura da forma mais elementar, ou seja, a leitura dos eixos, como na questão 151 da Figura 5.

A questão 146, entretanto, exige maior reflexão do estudante, pois não basta verificar qual a característica do produto com a maior média (maior coluna); é necessário avaliar os dados apresentados no gráfico, comparando as características do novo produto e dos dois concorrentes. 


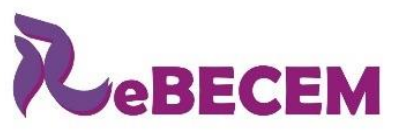

\section{Revista Brasileira de Educação em \\ Ciências e Educação Matemática}

DOI: http://dx.doi.org/10.33238/ReBECEM.2019.v.3.n.2.22636

Como as atividades nas estações eram realizadas em grupo, elas proporcionaram o debate e a reflexão coletiva. Garfield (2013) defende que o trabalho em grupo melhora a habilidade de comunicação, a capacidade de trabalhar em equipe e possibilita aos alunos reestruturar os novos conceitos estatísticos e adicioná-los em suas próprias estruturas cognitivas. Para Kenski (2008, p. 663), é necessário repensar o ato comunicativo com fins educacionais, o qual se realiza no diálogo, na troca, nas "múltiplas conexões entre as pessoas, unidas pelo objetivo comum de aprender e de conviver”.

Vale aqui ressaltar a importância de compreender o espaço educacional como um espaço social, onde a experimentação e o diálogo oportunizam ao estudante compreender e construir o seu atuar. Um processo de transformação na convivência, em que professores e estudantes se modificam de maneira congruente, enquanto permanecerem em interações recorrentes. O nosso viver se faz social enquanto aceita, acolhe, abre espaço ao outro como legítimo na convivência (MATURANA, 2006).

\section{3 Atividade 3: Projetos de Aprendizagem}

Após vivenciarem a participação em uma pesquisa como respondentes (Atividade 1), os estudantes terão a possibilidade de planejar e desenvolver uma pesquisa quantitativa. Assim, na metodologia dos Projetos de Aprendizagem, a aproximação dos conteúdos a serem abordados em sala de aula com o contexto dos alunos se efetiva, uma vez que o tema a ser investigado parte do interesse e da curiosidade deles. Tal escolha possibilita que concentrem sua atenção na atividade proposta, em razão de sua significância. Segundo Bartoszeck e Bittencourt (2017), o processo de contextualização do conhecimento favorece que as novas informações possam se ancorar nas vivências anteriores retidas na memória.

Em um Projeto de Aprendizagem, o estudante tem a oportunidade de desenvolver a sua curiosidade e o senso crítico e assumir uma atitude ativa na construção do conhecimento (SILVA; MENEZES; FAGUNDES, 2017). Essa atitude, por sua vez, desencadeia a motivação, também indispensável no processo de aprendizagem. Enquanto a emoção auxilia no registro das informações na memória de longo prazo, a motivação, com a liberação de uma substância denominada dopamina, ativa a região do bem-estar no cérebro, estimulando o estudante a focar a atenção na atividade proposta (IZQUIERDO, 2006). 
DOI: http://dx.doi.org/10.33238/ReBECEM.2019.v.3.n.2.22636

O Projeto de Aprendizagem vai sendo delineado pelos estudantes à medida que esses buscam por informações - encontradas em diversos materiais, como artigos científicos, sites da internet e livros - sobre o tema escolhido, de forma a refutar e/ou validar as dúvidas e as certezas sobre ele.

O compartilhamento de informações sobre o tema e a interação entre os estudantes refletir e reformular o planejamento do Projeto de Aprendizagem (SILVA; MENEZES; FAGUNDES, 2017). Segundo Bortoli e Teruya (2017, p. 74), “a interação permite o aumento das ligações entre os neurônios, e consequentemente, a formação de novos circuitos e a geração de um novo conhecimento". Esse, por sua vez, conforme Maturana (2006), é adquirido na convivência em um certo espaço, que pode ser a escola ou a universidade.

A partir das aprendizagens construídas no convívio com os colegas e no processo de coleta e elaboração das informações, os estudantes já podem iniciar a escrita da pesquisa, organizar a introdução e uma breve revisão da literatura, o que suscita a construção de novos conhecimentos sobre o tema escolhido. A revisão de literatura auxilia na elaboração de um instrumento de coleta de dados, o qual precisa conter questões sobre o perfil dos respondentes e sobre o tema investigado. Na elaboração desse instrumento, é possível retomar os conceitos estatísticos já discutidos na disciplina ou apresentar aqueles necessários para o desenvolvimento do Projeto de Aprendizagem.

Um dos conceitos abordados na elaboração do Projeto de Aprendizagem diz respeito a população e a métodos de amostragem. Com os dados já coletados, os estudantes escolhem, com o auxílio da professora, a forma mais adequada de apresentar e resumir os dados, seja por meio de tabelas, gráficos ou medidas estatísticas. A escolha do melhor gráfico para representar um determinado conjunto de dados está vinculada ao reconhecimento dos elementos que o constituem e das suas inter-relações. De acordo com Kanno (2013, p. 11), o fato de a informação gráfica ser, predominantemente, visual “[...] permite uma leitura mais rápida e compreensão mais imediata por parte dos leitores”.

A inter-relação entre os conceitos estatísticos auxilia na escolha das medidas estatísticas utilizadas para resumir a informação sobre os dados coletados, bem como destaca a complexidade das possibilidades de interpretação sobre a temática investigada no Projeto de Aprendizagem e o conhecimento que o aluno pode alcançar. Para Metring (2011, p. 98), “uma boa rede neural não necessariamente se forma pelo acúmulo de conteúdo, mas sim pela capacidade crítica da pessoa em descobrir se a solução encontrada foi adequada". 


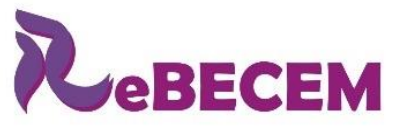

DOI: http://dx.doi.org/10.33238/ReBECEM.2019.v.3.n.2.22636
Revista Brasileira de Educação em

Ciências e Educação Matemática

As reflexões desenvolvidas por mim ao longo do Doutorado em Educação em Ciências instigaram ao uso dos Projetos de Aprendizagem como metodologia de ensino nas disciplinas de Estatística que ministro no Ensino Superior. A aplicação dessa metodologia aos estudantes dos cursos de Administração, Ciências Econômicas e Ciências Contábeis, com os quais trabalhei ao retornar do doutorado, foi analisada por Samá e Porciúncula (2017). A partir da análise do discurso dos estudantes, foi possível constatar que os Projetos de Aprendizagem promoveram uma associação entre os conceitos estatísticos e as aplicações práticas. Ainda segundo as autoras, a escolha do tema promoveu maior engajamento dos estudantes na realização da pesquisa, a qual, por envolver dados do seu interesse e cotidiano, garantiu maior significado para eles, como relatado por $83 \%$ dos estudantes. Apesar desse maior engajamento e interesse, Porciúncula e Samá (2014) observaram que uma pequena parcela de estudantes (17\%) apresentou dificuldade em aplicar os conteúdos trabalhados em sala de aula no desenvolvimento do PA. Essa dificuldade pode ser explicada pela falta de tempo e de cooperação entre os colegas do grupo, o que os levou a optar pela divisão de tarefas e prejudicou a realização do Projeto de Aprendizagem e a compreensão dos conceitos estatísticos.

Trabalhar com o outro, dividir responsabilidades, conviver em grupo são habilidades necessárias aos profissionais de várias áreas do conhecimento. O ensino dos conceitos estatísticos por meio da pesquisa, no Ensino Superior, viabilizado em um Projeto de Aprendizagem, pode auxiliar os estudantes a desenvolver tais habilidades. $\mathrm{O}$ educar pela pesquisa, nas disciplinas de Estatística, possibilita conviver e lidar com as incertezas inerentes ao próprio pesquisar e contribui para a formação de indivíduos com iniciativa e autonomia, conscientes dos problemas da atualidade, com sensibilidade para trabalhar com o outro e flexibilidade para lidar com o inesperado em um mundo em constante mudança (PORCIÚNCULA; SAMÁ, 2014).

Por outro lado, a complexidade do processo investigativo demanda, por parte do professor, habilidade para mediar a realização de uma pesquisa, pois, além do conhecimento estatístico básico sobre os conceitos, também se exigem dele a compreensão das relações entre as variáveis, a leitura e a interpretação dos dados. Tal constatação torna ainda mais premente a inserção de disciplinas de Estatística nos currículos dos cursos do Ensino Superior, em especial, nos de Licenciatura. 


\section{Considerações}

No presente relato busquei evidenciar o protagonismo, a criatividade e a autonomia dos estudantes na aprendizagem dos conceitos estatísticos, por meio de atividades mais descontraídas e contextualizadas. Essas foram fundamentadas na Teoria da Biologia do Conhecer e nos estudos da Neurociência Cognitiva, tendo em vista que planejar atividades que promovam uma aprendizagem ativa auxilia a compreensão dos conceitos estatísticos.

A primeira buscou subsídios na emoção e na interação no ambiente educacional. A segunda contribuiu para a aprendizagem ativa dos conceitos estatísticos, ao usar diferentes recursos didáticos, o que permitiu capturar a atenção dos estudantes e o registro das informações na memória de longo prazo. Na terceira, a possibilidade de o estudante escolher um tema de seu interesse para investigar mobilizou a motivação e a atenção, enquanto a emoção e a satisfação presentes ao longo da realização da atividade auxiliaram no registro das informações na memória.

As atividades aqui apresentadas também podem ser adaptadas e modificadas para atender estudantes de outros níveis de ensino e possibilitam explorar conceitos estatísticos para além dos que foram aqui abordados, dependendo da criatividade e da intencionalidade do professor. Com este relato, espero inspirar outros professores a repensar sua prática pedagógica, a fim de ajudar os estudantes a superar suas dificuldades na compreensão dos conceitos estatísticos.

\section{Referências}

ANDRADE, M. C. F.; SOUZA, P. R. Modelos de rotação do ensino híbrido: estações de trabalho e sala de aula invertida. E-Tech, Florianópolis, v. 9, n. 1, p. 03-16, 2016.

BACICH, L.; MORAN, J. M. Aprender e ensinar com foco na educação híbrida. Revista Pátio, Porto Alegre, n. 25, p. 45-47, jun. 2015. Disponível em: http://www.grupoa.com.br/revistapatio/ artigo/11551/aprender-e-ensinar-com-foco-na-educacao-hibrida.aspx. Acesso em: 10 jan. 2019.

BARTOSZECK, A. B.; BITTENCOURT, D. F. Alfabetização em Neurociência e Educação para professores do Ensino Fundamental e Médio: um estudo exploratório. Revista Paidéi@ Santos, v. 9, n.15, p. 1-27, jan. 2017.

BORTOLI, B.; TERUYA, T. K. Neurociência e Educação: os percalços e possibilidades de um caminho em construção. Imagens da Educação, Maringá, v. 7, n. 1, p. 70-77, 2017.

CAMPOS, C. R. et al. O ensino de gráficos estatísticos no contexto da educação crítica. In: CONFERÊNCIA INTERAMERICANA DE EDUCAÇÃO MATEMÁTICA 15., 2015, Tuxtla Gutiérrez, México. Anais... Tuxtla Gutiérrez, México: XV CIAEM, 2015. p. 165-172. 
DOI: http://dx.doi.org/10.33238/ReBECEM.2019.v.3.n.2.22636

CAVALCANTI, M. R. G.; NATRIELLI, K. R. B.; GUIMARÃES, G. L. Gráficos na mídia impressa. Bolema, Rio Claro, v. 23, n. 36, p. 733-751, ago. 2010.

CAZORLA, I. Estatística ao alcance de todos. In: ENCONTRO NACIONAL DE EDUCAÇÃO MATEMÁTICA, 8., 2004, Recife. Anais... Recife: VIII ENEM, 2004. p. 1-11.

CAZORLA, I. M.; SILVA JÚNIOR, A.V.; SANTANA, E. R. S. Reflexões sobre o ensino de variáveis conceituais na educação básica. REnCiMa, São Paulo, v. 9, n. 2, p. 354-373, 2018.

CORDANI, L. K. Caminhos da Educação Estatística ao longo do tempo: uma leitura pessoal. Jornal Internacional de Estudos em Educação Matemática, São Paulo, v. 8, n. 3, p. 154-178, 2015.

COSENZA, R.; GUERRA, L. Neurociência e educação: como o cérebro aprende. 1. ed. Porto Alegre: Artmed, 2011.

GAL, I. Adult's statistical literacy: Meanings, components, responsabilities. International Statistical Review, The Netherlands, v. 70, n. 70, p. 1-25, abr. 2002.

GARFIELD, J. Cooperative learning revisited: From an instructional method to a way of life. Journal of Statistics Education, Alexandria, v. 21, n. 2, p.1-9, 2013.

GAZZANIGA, M. S. et al. Neurociência cognitiva: a biologia da mente. 2. ed. Porto Alegre: Artmed, 2006.

GOULART, A.; COUTINHO, C. Q. S. Letramento estatístico e o Exame Nacional do Ensino Médio. In: SAMÁ, S.; PORCIÚNCULA, M. Educação Estatística: ações e estratégias pedagógicas no Ensino Básico e Superior. 1. ed. Curitiba: CRV, 2015. p. 145-153.

IZQUIERDO, I. Memória. 1. ed. Porto Alegre: Artmed, 2006.

KANNO, M. Infografe: como e porque usar infográficos para criar visualizações e comunicar de forma imediata e eficiente. 1. ed. São Paulo: INFOLIDE, 2013. Disponível em: https://designlyn.files.wordpress.com/2014/06/infografemariokannopagsimples-130822154840phpapp02.pdf. Acesso em: dezembro de 2018.

KENSKI, V. Educação e Comunicação: interconexões e convergências. Educação \& Sociedade, Campinas, v. 29, n. 104 - especial, p. 647-665, out. 2008.

LENT, R. Cem bilhões de neurônios: conceitos fundamentais da neurociência. 1. ed. São Paulo: Atheneu, 2004

MATURANA, H. R. Cognição, ciência e vida cotidiana. 1. ed. Belo Horizonte: UFMG, 2006.

MATURANA, H. R.; VARELA, F. A árvore do conhecimento: as bases biológicas da compreensão humana. 5. ed. São Paulo: Palas Athena, 2005.

METRING, R. A. Neuropsicologia e aprendizagem: fundamentos necessários para planejamento do ensino. 1. ed. Rio de Janeiro: Wak, 2011.

MORAN, J. Metodologias ativas para uma aprendizagem mais profunda. In: BACICH, L.; MORAN, J. (org.). Metodologias ativas para uma educação inovadora. 1. ed. Porto Alegre: Penso, 2018. p. 1-25. 
DOI: http://dx.doi.org/10.33238/ReBECEM.2019.v.3.n.2.22636

PEREIRA, F. A.; SOUZA, F. S. O Exame Nacional do Ensino Médio e a construção do letramento e pensamento estatístico. Educ. Matem. Pesq., São Paulo, v.18, n.3, p. 1319-1343, 2016.

PORCIUNCULA, M.; SAMÁ, S. P. Teaching Statistics through learning projects. Statistics Education Research Journal, Auckland, v.13, n. 2, p.177-186, nov. 2014.

RODRIGUES, P. F. S. Processos cognitivos visuoespaciais e ambiente visual circundante: implicações educacionais. Psicologia: Teoria e Pesquisa, Brasília, v. 32, n. 4, p. 1-10, 2016.

SAMÁ, S. P. et al. Aspectos neurocognitivos da aprendizagem na sala de aula de Estatística. In: LOPES, C. E.; PORCIÚNCULA, M.; SAMÁ, S. (org.) Perspectivas para o ensino e a aprendizagem de Estatística e Probabilidade. 1. ed. Campinas: Mercado de Letras, 2019. p. 271-295.

SAMÁ, S. P.; MOURA, G. M.; SANTOS, F. O. Ensino de Estatística e os nativos digitais: uma proposta para formação inicial de professores. Caminhos da Educação Matemática em Revista, Aracaju, v. 9, n. 2, p. 48-62, 2019.

SAMÁ, S. P.; PORCIÚNCULA, M. Percepção dos estudantes em relação ao ensino de estatística fundamentado no Modelo Pedagógico Relacional. In: ENCONTRO

INTERNACIONAL DE FORMAÇÃO DE PROFESSORES, 10., FÓRUM PERMANENTE DE INOVAÇÃO EDUCACIONAL, 1., 2017, Aracaju. Anais... Aracaju: UNIT, 2017. p. 1-16. Disponível em: https://eventos.set.edu.br/index.php/enfope/article/viewfile/5029/1487. Acesso em: 25 jun. 2018.

SILVA, P. F.; MENEZES, C. S.; FAGUNDES, L. C. Avaliação processual no contexto de Projetos de Aprendizagem. Informática na Educação: teoria \& prática, Porto Alegre, v. 20, n. 1, p. 27-35, jan./abr., 2017.

SOUZA, F. S.; SILVA, A. S. Possibilidades didáticas para o desenvolvimento do letramento estatístico na Educação Básica. In: LOPES, C. E.; PORCIÚNCULA, M.; SAMÁ, S. (org.). Perspectivas para o ensino e a aprendizagem de Estatística e Probabilidade. 1. ed. Campinas: Mercado de Letras, 2019. p. 91-124.

TYNG, C. M. et al. The influences of emotion on learning and memory. Frontiers in Psychology, Brussels, v. 8, n. 1454, p. 1-22, 2017.

VALENTE, J. A. A comunicação e a Educação baseada no uso das tecnologias digitais de informação e comunicação. Revista UNIFESO-Humanas e Sociais, Rio de Janeiro, v. 1, n. 1, p. 141-166, 2014.

Recebido em: 26 de junho de 2019.

Aceito em: 20 de agosto de 2019. 